\title{
REFLEXIONES SOBRE LA EDUCACIÓN AFECTIVA EN LA ESTELA DE LA RATIO
}

DOI: https://doi.org/10.52039/seminarios.v63i219.94

ALONSO MORATA MOYA

\section{EDUCAR PARA SABER MANEJAR LOS SENTIMIENTOS}

Los sentimientos son un regalo de Dios; ellos proporcionan color y sabor a nuestra vida. Si es cierto que no debemos confundir sentimientos con afectos, tenemos que subrayar que están en íntima unión: el sentimiento es el movimiento (positivo o negativo) hacia una persona, el afecto muestra el grado de intensidad de ese sentimiento y su carácter (positivo o negativo).

Para que no nos traicionen los sentimientos hemos de mandar en ellos (en la medida de lo posible), de lo contrario nos puede suceder como a José en el banquete con sus hermanos. Llega un momento en el que no puede disimular, la marea de su mundo sentimental se eleva hasta el punto de tener que dejar el comedor para no emocionarse delante de ellos, mejor, para no mostrar sus sentimientos (cf. Gn 45).

A lo largo de la formación para el ministerio nos hemos encontrado con educadores y seminaristas que han sido muy espontáneos en sus manifestaciones, sobre todo, mostrando sus «preferencias». Si se dan en el seminarista es menos grave, porque un buen educador puede tomar pie de ellas para encauzarlas hacia la maduración, peor si estas manifestaciones son por parte de un formador, entonces puede el seminarista verse envuelto en un lazo afectivo que le impedirá madurar y, en ocasiones, creará un vínculo que no le permitirá asumir libremente sus determinaciones.

2. ¿CÓMO EDUCAR EN LA SANA AFECTIVIDAD?

1. Comenzar desde abajo

He tenido la gran suerte de estar de rector en un seminario menor durante once años seguidos. Los alumnos, entre 12 y 17 años, superaron siempre el centenar. 
Una de las exigencias en su paso por el Seminario Menor era el cultivo de las virtudes humanas y había que ponerles ante situaciones sencillas, cotidianas y apreciar su modo de responder, su reacción. Era importante ver cómo afrontaban y resolvían problemas sencillos. Cierto que hay que partir de un mínimo de cualidades personales y potenciarlas en la vida diaria. No podemos obviar que la persona es un ser en continua dinámica y que un gran porcentaje de lo que será en la edad adulta se va generando y consolidando a lo largo de su adolescencia.

He sentido el gozo de tener como alumnos a niños de una calidad humana, una generosidad, una apertura, una sinceridad poco corrientes, muchachos que me han enseñado a ser para los demás; normalmente su crecimiento ha ido en la línea de progresividad, madurez, confianza en el Señor, con los sacerdotes del seminario y entre sus compañeros. Pero también jovencitos nerviosos, inquietos, que no dejaban nada sereno a su paso, que se han ido convirtiendo en adolescentes, jóvenes y adultos equilibrados, sin perder esa «inquietud». Es muy importante que todos aquellos que pasan por el Seminario no pierdan su personalidad por querer que sean todos según un patrón determinado, que muchas veces es artificial y pasajero.

Si educar es ayudar a que aflore lo bueno que hay en cada persona y potenciarlo, este es uno de los fines más importantes de la etapa del Seminario Menor. Lugar que, en mi opinión, habría que recuperar, porque hoy en día los ambientes para educar a niños y adolescentes (sobre todo a los que muestran deseos de emprender un camino de entrega) no son los mejores. Esto no supone que se les aísle del mundo, sino que se le den armas de madurez para poder afrontar y saber manejar afectivamente la realidad que le rodea.

El joven (niño, adolescente) seminarista ha de ir adquiriendo en su configuración una doble identidad, como persona y como servidor del pueblo de Dios, a la manera y semejanza de Jesús de Nazaret. El trato con su familia y con sus coetáneos es importante a la hora de discernir su paso al Seminario Mayor; sin olvidar, por supuesto, la cuidadosa comprobación de que se hayan consolidado en él aquellas cualidades que resultan necesarias para ser un buen pastor, el sentido positivo de la castidad, la capacidad de sintonizar con los demás, la apertura y la capacidad de entrega, la simpatía. Libre de casi todas las manías (alguna hay que tener, aunque la llamemos hobby, porque no dejan de ser rasgos de nuestra personalidad escondida). 


\section{Las vocaciones de adultos}

Nos habla la Ratio de las vocaciones de adultos. Tengo la seguridad de que la mayoría de los que entran al seminario después de un recorrido por la vida, de una auténtica experiencia de Dios que les ha llevado a la conversión o de una vida cristiana que se ha intensificado precisamente al sentir la llamada de Dios, son en general jóvenes-adultos con recta intención. No obstante, hay que estar muy atentos a su tenor de personalidad, porque llegan ya con una configuración propia, la cera está ya un poco dura y reblandecerla a fuerza de fuego puede ser peligroso.

Mi experiencia es que, si son valiosos (que la mayoría lo son) hay que situarse con ellos en el tramo del camino en el que se encuentren, entender que no han hecho éste como los que provienen del Menor, han tenido vivencias y experiencias propias...

Todo acompañamiento en la formación sacerdotal supone un ponerse al lado de, como hace con el eunuco de Candaces, Felipe, subirse al carro con él y desaparecer cuando ha cumplido su misión, pero subirse y estar con él todo el tiempo que necesite para discernir. Cuando diga: "¿Qué impide que me bautice?», será el momento de que siga el camino en el carro de su vida. $Y$ tal vez con otros acompañantes.

En este punto creo importante la implantación del Curso propedéutico que reclama la Ratio; y no como un momento a pasar, sino como clave para calibrar el «estado de salud del aspirante». Ninguna de las sugerencias de la Ratio debe pasarse a nota de inventario, lo que si es preciso es que nos tomemos en serio la implantación de este Propedéutico, uniendo un buen grupo de seminaristas (o aspirantes) con el objeto de hacer un arranque de camino lo más uniforme posible, dentro del total respeto a las peculiaridades y al ritmo de cada uno, pero también al grado de madurez que han de tener.

A este respecto señala la Ratio:

Es necesario evaluar el tiempo transcurrido entre el Bautismo, o la conversión cristiana, y el ingreso en el Seminario, evitando la posible confusión entre el seguimiento de Cristo y la llamada al ministerio presbiteral (CIC can. 1042, n. 3)... [Conviene que] se cuide el acompañamiento de estos candidatos a través de un proceso serio, que prevea, en el ámbito de la vida comunitaria, una sólida formación espiritual y teológica, mediante un oportuno método pedagógico y didáctico, que tenga en cuenta el propio perfil personal (Ratio 24, § 2-3).

La recomendación de que no se hagan excepciones en cuanto al acompañamiento es muy oportuna, porque, a veces, el hecho de que sean per- 
sonas que tienen experiencia y que «saben lo que hacen» -dicen- puede llevarnos a pensar que no precisan de mucho acompañamiento. La realidad es muy distinta, necesitan tanto o más que los niños y adolescentes que han ido haciendo elecciones en cada etapa de su maduración y de ellos se ha podido contrastar el grado de madurez alcanzado. Junto a ello hay que detectar que no se dé el «síndrome de los conversos» que puede confundir a los demás desde la no claridad en el interior de ellos mismos y les obliga, en ocasiones, a hacer sublimación y enconchar problemas, provocados por sucesos de su pasado reciente que ahora molestan y, en lugar de asumirlos, ponerlos sobre la mesa y realizar una «terapia de normalización», se empeñan en negárselos a sí mismos, con lo cual no parecen tener mucha confianza en la misericordia del Padre y en la capacidad sanadora de asumir los defectos o pecados y ponerse a la tarea de una curación total.

Otro tanto sucede con las vocaciones indígenas que deben recibir una formación arraigada en las coordenadas y cultura de sus ambientes. Tener en cuenta sus peculiaridades y los así llamados «puntos flacos de su estructura cultural» para fortalecer su dinámica de maduración en los años de Seminario, sin dejar nunca el acompañamiento (esto vale para todos, porque hemos tenido jóvenes que han mostrado una «madurez aparente» que no ha ido "des-enmascarada», sino cuando las situaciones concretas les han hecho sentirse perdidos, quizás por falta de sinceridad y apertura ante los formadores o, también, porque ni ellos ni los formadores habían detectado tal problema, tal rendija en la fortaleza de su existencia.

Asimismo, conviene prestar atención a quienes, procedentes de otra cultura, quieren incorporarse a nuestros presbiterios. Dada la escasez de respuestas al sacerdocio en muchas diócesis -tal vez sin suficiente discernimiento- reciben a jóvenes de otros países. Ciertamente la Iglesia es universal, pero la buena voluntad no exime de establecer y llevar a cabo un proceso de maduración e inculturación en la diócesis a la que se incardinan y de comprobación de su integración en ella; en caso contrario ya sabemos que, en lugar de ayudar a la evangelización de las diócesis se crean problemas que antes no existían en el clero de la misma. En absoluto dudo de que hay sacerdotes procedentes de otros lugares que se han hecho "de la tierra» y están haciendo una notable labor evangelizadora y, si pasan el tiempo de su formación aquí (o en país distinto al suyo) conviene que también estén atentos a sus orígenes culturales, porque lo más sano es que, después de unos años de ministerio en la Iglesia que les ha acogido, vuelvan a sus respectivas diócesis. 


\section{La formación por etapas y la correspondencia con la madurez}

El logro de los objetivos formativos no depende necesariamente del tiempo transcurrido en el Seminario ni de los estudios realizados. Por tanto, no se debe llegar al sacerdocio en razón de haber concluido las etapas propuestas previamente en una sucesión cronológica, casi «automáticamente», sin considerar los progresos efectivamente logrados en una maduración integral (Ratio 59).

Por varias razones quisiera destacar este punto; no en vano, conocemos a compañeros, muy brillantes en estudios que no deberían haber sido ordenados, ya que su madurez o algunas tendencias de las que no eran conscientes, han hecho -pese a que su alta preparación presagiara lo contrario- que tuvieran que abandonar el ejercicio del ministerio o sentirse frenados e incapacitados en un auto-ostracismo muy penoso. Compañeros de mi promoción que esperaron el tiempo oportuno, accedieron al presbiterado uno o dos años más tarde y han sido y son buenos sacerdotes, con su «carga personal» como todos, pero fieles, trabajadores y entusiastas.

\section{a) Los fines de maduración en la etapa Propedéutica}

Claramente lo expone la Ratio: el discernimiento sobre la conveniencia de continuar el camino sacerdotal o seguir otro camino de vida. Es patente que en el camino de formación sacerdotal tiene que haber una total libertad de elección. La respuesta no se puede exigir desde una estrategia de «caza o pesca» (los cotos), si se invita a algún joven a que siga este camino, la invitación no supone un forzar a, se trata de proponer y discernir inmediatamente si ese es su camino. Desde hace años estoy convencido de que Dios pone todos los ingredientes para la felicidad de cada uno en el camino al que Él le invita, y si elige equivocadamente, muchas de esas «gracias» que había puesto en el itinerario de su vida o no se harán realidad en otro caminar o lo harán con menos intensidad. La mejor respuesta para cada uno y para el bien de los que tienen que recibir su «ministerio» es la que responde a la llamada que Dios le ha hecho. Por eso es muy importante este primer momento y lo es también para aquellos que han comenzado en el Seminario Menor. El inicio en la oración, la convivencia, la liturgia de la Palabra... El inicio en una experiencia «parroquial y caritativa» le ayudará a desarrollar la «dinámica del don de sí».

Hasta ahora no se ha llevado a cabo esta etapa tal como la demanda la Ratio y parece que habrá que unir fuerzas para responder a la conveniencia de que se haga en un edificio distinto del Seminario Mayor y con 
un equipo de formadores que ayuden a realizar el objetivo de maduración humana y cristiana, así como la acertada selección de los candidatos.

\section{b) La etapa discipular}

Discípulo es aquel que ha sido llamado por el Señor a estar con Él (Mc 3, 14), a seguirlo y a convertirse en misionero del Evangelio. El discípulo aprende cotidianamente a entrar en los secretos del Reino de Dios, viviendo una relación profunda con Jesús. Este «permanecer» con Cristo implica un camino pedagógico-espiritual, que transforma la existencia, para ser testimonio de su amor en el mundo (Ratio 61).

Creo que hay dos ideas fundamentales que marcan la finalidad de maduración en esta etapa discipular: el aprender a estar con Él y el transformar la existencia.

Esta última nos lleva pensar que no es lo mismo saber manejar los sentimientos que manejar a los demás con los sentimientos (servirse de los sentimientos y afectos para manipular al otro). Manejar los sentimientos supone una madurez, que se manifiesta en usarlos en provecho de los otros, sin dejar nunca herido al que dirige su amor, compasión y misericordia; uno se siente afectado por la vida del otro, pero, de ninguna manera, afectando y esclavizando con los lazos de los sentimientos a la otra persona. Es un modo de ayudar a la libertad. Jesús nos envuelve con su amor y nos seduce, pero deja libre para que se le siga o no (¿también vosotros queréis iros?). De la misma manera, el aspirante a servir en el misterio de presbítero debe dar amor que libera. Nunca puede ser un «do ut des», sino una donación desinteresada.

Para ello es preciso que en esta etapa comience la experiencia del discipulado, que comprende toda la vida, y cumpla lo que Marcos nos dice: los llamó para que estuvieran con Él. Superando falsos misticismos, es la experiencia de que Jesús vive, está, acompaña y... nos la juega algunas veces (aparentando vacío para que le busquemos más y mejor); se trata de la única experiencia que nos va madurando en la dimensión de entrega y servicio. Podemos afirmar que la dimensión humana y el crecimiento espiritual han de ir a la par. La Ratio nos lo dice así:

Durante el proceso de formación nunca se insistirá suficientemente sobre la importancia de la formación humana; la santidad de un presbítero, de hecho, se injerta en ella y depende, en gran parte, de su autenticidad y de su madurez humana. La carencia de una personalidad bien estructurada y equilibrada se constituye en un serio y objetivo impedimento para la continuidad de la formación para el sacerdocio (Ratio 63). 
Nos recuerda seguidamente la educación del carácter, la fortaleza de ánimo, las virtudes humanas: lealtad, justicia, fidelidad, amabilidad. Todo en un proceso formativo, un proceso que no finaliza nunca, porque el ser humano está en continuo estado de maduración, ya que cada época de la vida tiene aspectos propios que hay que poner a punto y en sazón.

Es cierto que no podemos dejar únicamente a merced de los elementos «pedagógicos» la madurez del candidato al ministerio, porque esta madurez humana «es suscitada y favorecida por la acción de la gracia, que orienta el crecimiento de la vida espiritual. Esta última dispone al seminarista a vivir en la presencia de Dios, en una actitud orante, y se funda en su relación personal con Cristo, que consolida la identidad discipular» (Ratio 64, § 1).

La exigencia de que exista una libertad y madurez interior adecuada, es necesaria para ese momento de ofrecimiento del seminarista, al que la Iglesia escoge y llama para que se prepare a recibir, en su momento, la sagrada ordenación.

\section{c) La etapa configuradora (estudios teológicos)}

Desde el primer momento vocacional... toda la vida del presbítero es una formación continua: la propia del discípulo de Jesús, dócil a la acción del Espíritu Santo para el servicio de la Iglesia (Ratio 68).

Quienes desde niños iniciamos el camino del seguimiento para servir al pueblo en el ministerio sacerdotal hemos tenido la experiencia de que, cuando llegábamos al fin de una etapa, configurándonos con Cristo, de acuerdo con las características de la misma, superados algunos de los «huecos de la personalidad» y rellenándolos con el buen material de la gracia, actualizada mediante el acompañamiento, que te ayudaba a discernir lo que había que elegir en cada momento para madurar en el proceso, sabemos que cada edad tiene sus "glorias y sus deficiencias», que nunca se puede decir que se ha completado el camino, ni se ha llegado a la madurez total.

Esta etapa configuradora debe estar marcada más que por los estudios, «por la formación espiritual propia del presbítero». Espiritualidad a imagen de Cristo: de fortaleza, ternura, sabiduría (no sólo conocimientos), capacidad de escucha en la oración y en los acontecimientos de la vida. De ahí que, aunque el sacerdote lo es de la Iglesia universal, es muy importante que se preparen para ejercer el ministerio en un contexto determinado. 
Nunca se debe creer que todo esté finalizado tras la ordenación presbiteral. Desde ese momento comienza un camino (en cierto modo en solitario) y se necesita, sobre todo para el sacerdote diocesano secular, un acompañamiento y una nueva forma de vivir en comunicación con sus compañeros. Entregado a la misión, en total sintonía con el pueblo al que sirve, debe vincularse al presbiterio diocesano, también el sacerdote religioso. «Eso significa adaptar el propio modo de sentir y actuar, en comunión con el obispo y los hermanos sacerdotes, por el bien de una porción del pueblo de Dios» (Ratio 71).

\section{EdUCAR AL CANDIDATO AL MINISTERIO PRESBITERAL ${ }^{1}$}

En una charla del doctor Rojas sobre formación sacerdotal proponía el símil de la construcción de un barco: «Al construir un barco, nos hacemos tres preguntas: 1) ¿Cómo construir una embarcación y gobernarla? 2) ¿Cómo mantenerse a flote? 3) ¿Cómo llegar a buen puerto?».

Estas tres preguntas metafóricas, yo las cambiaría y las formularía de otra manera: ¿quién soy yo?, ¿qué va a ser de mí? y ¿dónde estoy? Hay una información que se le da al navegante, del tipo de viento, de las características del mar. El mar es muy traicionero, la vida se embosca y si no estamos bien pertrechados, nos pasan cosas graves y serias:

-¿Quién soy yo? remite a mi personalidad: yo soy alguien que reside, se hospeda y habita en una personalidad; tengo mi forma propia de ser.

-¿Qué va a ser de mí? De mí va a ser lo que yo haga con mi proyecto de vida, un proyecto coherente y realista de vida (cf. más adelante los indicadores y el decálogo que proponemos).

- ¿Dónde estoy? Suele pasarnos a menudo que como la vida va muy de prisa, no sabemos dónde estamos. Frente a la prisa de la vida, la calma de la teoría.

Estas tres preguntas las vamos a intentar ir respondiendo; son fundamentales, nos van a llevar a una aproximación de lo que es una persona madura. La madurez es un concepto relativo, no absoluto, no existe una madurez total, sino parcial. ¿Por qué? Porque la vida es larga, compleja y cambiante.

1. El texto que sigue es parte de la Conferencia que el Doctor Rojas dio en la Comisión de Seminarios y Universidades en septiembre de 2016. Encuentro de Rectores y Formadores de los Seminarios Mayores. El texto es suyo, los errores de mi resumen. 
Antes de seguir adelante, reflexionemos sobre algunas etimologías. La palabra personalidad viene de la tradición grecolatina. Alude en primer lugar a la máscara que se ponían los actores del teatro durante la representación. Gracias a esa máscara resonaba la voz del actor. En segundo lugar, remite a unidad sintética del individuo, que se refleja en su rostro singular. Por consiguiente, la personalidad evoca, fundamentalmente, las partes descubiertas del cuerpo que son la cara y las manos. De hecho muchas veces decimos "su cara no me gusta», "tenía mala cara», "la cara que puso», «dio la cara». Así pues, una primera definición sería: «La personalidad es la suma total de pautas de conducta, actuales y potenciales, que residen en un individuo y que se mueve entre tres arbotantes fundamentales: 1) la herencia, la tercera parte de nuestra personalidad es hereditaria, a esto se le llama temperamento: dice la gente tiene el mismo temperamento que su padre, es decir, el código genético viene ahí; 2) el carácter, que es la parte adquirida de la personalidad; y 3 ) la biografía. La vida es la edad nuestra, enseña más que muchos libros, pues aporta el saber experiencial. «La experiencia humana es un saber acumulado, que está ahí en el subsuelo nuestro, sin darnos cuenta» (Julián Marías).

Otra definición de la personalidad que nos acerca a su registro: La personalidad es una estructura organizada y dinámica en donde se agrupan aspectos físicos (contenidos principalmente en nuestra morfología del cuerpo), psicológicos (patrimonio de ingredientes que están dentro de nosotros: percepción, memoria, pensamiento, inteligencia conciencia), sociales (todo aquello que se deriva del contacto con los demás), culturales (tradición y estética) y espirituales (religación al Otro). Todo ese bloque forma un magma y da lugar como resultante a un estilo, a una manera. En el frontispicio del templo de Apolo podía leerse: "Conócete a ti mismo», frase que resume la tarea a la que está llamado todo hombre a lo largo de su vida.

La personalidad podemos decir que es como una orquesta, donde diversos y variados instrumentos son ensamblados por el director de orquesta, que es la identidad personal, la persona. La persona es capaz de englobar, de conjugar, de resumir todo aquello dando lugar a una sinfonía que es el comportamiento de cada uno, con su sello propio.

Pues bien la personalidad es trasparente y opaca, es lúcida y críptica, es apolínea y dionisiaca. Es forma de percibir, de sentir, de pensar, de reaccionar y de comportarse. Eso da lugar a la conducta individual, con sello propio. Por lo tanto, la personalidad es una forma de relacionarse con uno mismo, con los demás y con la realidad. 
Con vistas a ayudar al formador y acompañante en la tarea educativa, señalamos a continuación diez indicadores para evaluar la madurez de la personalidad de los candidatos:

1. Haber tenido un modelo de identidad. En el momento presente los modelos de identidad están rotos, partidos por la mitad. El modelo de identidad es alguien en el que yo me veo reflejado y me gustaría parecerme a él.

Tres modelos, el profesor, el maestro y el testigo: a) el profesor enseña una asignatura, y se queda ahí; después viene el maestro, entre los dos están el padre y la madre. b) El maestro enseña lecciones que no vienen en los libros. Al alumno le gustaría parecerse al maestro. c) El testigo es una lección abierta de vida, es un ejemplo de coherencia, de sensatez, de alegría, de vitalidad. No tiene que hablar. Es su vida, es la trayectoria de él. Hoy tenemos muchos profesores, pocos maestros y escasos testigos.

2. El segundo síntoma de una personalidad madura es tener un buen equilibrio entre corazón y cabeza. El hombre maduro mezcla con arte y oficio la vida afectiva y la vida racional. Ni demasiado sensible ni demasiado frío, sino las dos cosas a la vez mezcladas armónicamente. Un famoso psicólogo americano, Goleman, autor de La inteligencia emocional, hace este planteamiento: el hombre inteligente no es alguien que saca en un test un resultado extraordinario, sino aquel que mezcla, según el momento y la circunstancia, el mundo de las emociones y los sentimientos con la esfera de la razón. Dice Kafka: «El corazón del hombre es una casa con dos estancias, en una bate la alegría y en otra la tristeza». Y dice la leyenda de Lot, que no conviene nunca reír demasiado fuerte, porque se puede despertar a la tristeza que está en la región vecina. Alegría y tristeza.

3. Un tercer indicador de la madurez es tener un proyecto de vida equilibrado. Y el proyecto de vida es un programa personal en donde hay, están, viven, suben, bajan, saltan, se mueven cuatros grandes argumentos: amor, trabajo, cultura y amistad. Hoy son frecuentes los «hombres light», es decir, sin sustancia, sin hondura. Un verdadero proyecto de vida puede muy bien comprenderse contrastándolo con las cuatro notas que definen esta forma de entender la vida. La primera de ellas es el hedonismo, lo importante es pasarlo bien; sin embargo, la clave de la vida es mirar en favor del que me rodea. La segunda es el consumismo, tanto tienes tanto vales; sin embargo, la clave está en ser. La tercera es la permisividad, haz lo que quieras, atrévete; sin embargo, el control personal ayuda a crecer. $Y$ la cuarta es el relativismo, nada es bueno o malo; sin embargo, la persona cabal es la que tiene capacidad para discernir moralmente. 
4. Una persona madura tiene una filosofía de vida, es decir, otorga a la vida un sentido. Esta filosofía se manifiesta especialmente ante la muerte. No en vano, la muerte se revela como esencial y decisiva, como un examen: mueres como has vivido (Jean Guitton). Esta filosofía ha de tener el menor número posible de contradicciones, además de referentes claros que resistan las circunstancias que vayan aconteciendo.

5. Una persona madura ha de tener autocontrol: el gobierno más importante es el gobierno de uno mismo. Y al mismo tiempo saber que todos somos débiles. Hemos de pensar, cada uno en nuestro fuero interno qué podemos hacer por los demás, con cabeza, con sentido, con modernidad.

6. Otro síntoma de madurez es tener una relación sana con el tiempo. Hay dos tipos de tiempo, el tiempo objetivo, que es el tiempo del reloj, y el tiempo subjetivo, que es el interior. Aquí me refiero al tiempo histórico, pasado, presente, futuro. Una personalidad madura es aquella que vive instalada en el presente, ha sido capaz de asumir y de cerrar las heridas del pasado, y vive empapada hacia el porvenir. La felicidad consiste en tener buena salud y mala memoria. La capacidad para pasar las páginas negativas del pasado es salud mental.

7. Índice de madurez es la capacidad para la convivencia. La convivencia siempre es difícil. Decía Lord Byron: «Es más fácil morir por una mujer que vivir con ella». La convivencia es compleja, es el arte de ceder, de estar pendiente del otro, de hacer la vida fácil a los demás, es la artesanía de lo pequeño... También, por lo que respecta a la convivencia, lo decisivo es «tener vida interior».

8. Una persona madura es aquella que tiene situada la sexualidad en tercer o cuarto plano de sus intereses personales, salvo que se trate de un adolescente o de un joven. Pensemos en la invitación permanente al sexo que inunda nuestra sociedad. Existen dos tipos de sexualidad: el sexo entendido sin amor y el sexo como amor comprometido. El sexo desvinculado del amor se caracteriza por el individualismo y el anonimato; el sexo como amor comprometido se caracteriza por la implicación de cuatro dimensiones en la relación con el otro: la física, la psicológica, la espiritual y la biográfica.

9. Una persona madura es aquella que tiene una buena educación de la voluntad. Para los psicólogos y los psiquiatras resulta imprescindible disponer de una «inteligencia instrumental», que integra aquellas herramientas de la inteligencia que se potencian a través del orden, la constan- 
cia, el esfuerzo y la motivación. Y la voluntad es la joya de la corona, es decir, no hay en el patrimonio psicológico nada tan importante como ella, exceptuando la inteligencia.

10. Por último, una persona madura es aquella que tiene un sano sentido del humor, o sea, la capacidad para reírse de sí misma, para desdramatizar, para ver las cosas con cierta perspectiva... En esta línea, yo diría que la madurez es precisamente saber darles a las cosas que nos pasan la importancia que realmente tienen.

\section{VALORACIÓN}

La felicidad es la aspiración, la vocación natural del ser humano. La felicidad consiste en un estado de ánimo, en estar contento con uno mismo, en la búsqueda constante de una personalidad madura.

Ante todo se trata de buscar el equilibrio y de poner en marcha un proyecto de vida coherente con estas cuatro notas que he glosado: amor, trabajo, cultura y amistad. En definitiva, la felicidad es suma y compendio de la vida auténtica.

Tomás Moro murió ajusticiado en 1535. Murió en soledad, confiscados sus bienes y desprestigiado socialmente su nombre. Sin embargo, sus últimas palabras, contenidas en su obra Escritos desde la cárcel, están repletas de felicidad, de una felicidad sólida y resistente, madura y realista, esperanzada y positiva. $Y$ es que la felicidad no depende de las circunstancias que nos rodean ni de los sucesos que nos acontecen, sino de su interpretación, del peso que concedo a cada uno y de la importancia que los otorgo.

Termino con Lao Tse (siglo $\mathrm{V}$ a.C.), cuyo pensamiento puede resumir un poco lo que he querido decir: «El que conoce el exterior es erudito, el que se conoce a sí mismo es sabio, el que conquista a los demás es poderoso y el que se conquista a sí mismo es invencible» (Cántico). 